\title{
Possible role of acylphosphatase, Bcl-2 and Fas/Fas-L system in the early changes of cardiac remodeling induced by volume overload
}

\author{
C. Nediani ${ }^{\mathrm{a}}$, A. Celli ${ }^{\mathrm{a}}$, L. Formigli ${ }^{\mathrm{b}}$, A.M. Perna ${ }^{\mathrm{c}}$, C. Fiorillo $^{\mathrm{a}}$, V. Ponziani ${ }^{\mathrm{a}}$,

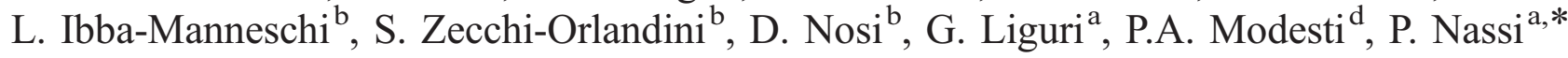 \\ ${ }^{\mathrm{a}}$ Department of Biochemical Sciences, University of Florence, Viale Morgagni 50, 50134 Florence, Italy \\ ${ }^{\mathrm{b}}$ Department of Human Anatomy and Histology, University of Florence, 50134 Florence, Italy \\ ${ }^{\mathrm{c}}$ Department of Experimental Surgery, University of Florence, 50134 Florence, Italy \\ ${ }^{\mathrm{d}}$ Clinica Medica Generale e Cardiologia, University of Florence, 50134 Florence, Italy
}

Received 17 October 2002; received in revised form 8 May 2003; accepted 26 May 2003

\begin{abstract}
To identify early adaptive processes of cardiac remodeling (CR) in response to volume overload, we investigated the molecular events that may link intracellular $\mathrm{Ca}^{2+}$ homeostasis alterations and cardiomyocyte apoptosis. In swine heart subjected to aorto-cava shunt for 6, 12, 24, 48 and $96 \mathrm{~h}$ sarcoplasmic reticulum (SR) $\mathrm{Ca}^{2+}$ pump activity was reduced until $48 \mathrm{~h}(-30 \%)$, but a recovery of control values was found at $96 \mathrm{~h}$. The decrease in SR $\mathrm{Ca}^{2+}$-ATPase (SERCA2a) expression at $48 \mathrm{~h}$, was more marked ( $-60 \%$ ) and not relieved by a subsequent recovery, while phospholamban (PLB) concentration and phosphorylation were unchanged at all the considered times. Conversely, acylphosphatase activity and expression significantly increased from 48 to $96 \mathrm{~h}(+40 \%)$. Bcl-2 expression increased significantly from 6 to $24 \mathrm{~h}$, but at $48 \mathrm{~h}$, returned to control values. At $48 \mathrm{~h}$, microscopic observations showed that overloaded myocardium underwent substantial damage and apoptotic cell death in concomitance with an enhanced Fas/Fas-L expression. At 96 h, apoptosis appeared attenuated, while Fas/ Fas-L expression was still higher than control values and cardiomyocyte hypertrophy became to develop. These data suggest that in our experimental model, acylphosphatase could be involved in the recovery of SERCA2a activity, while cardiomyocyte apoptosis might be triggered by a decline in Bcl-2 expression and a concomitant activation of Fas.
\end{abstract}

(C) 2003 Elsevier B.V. All rights reserved.

Keywords: $\mathrm{Ca}^{2+}$ pump; Sarcoplasmic reticulum; Apoptosis; Hypertrophy; Acylphosphatase, Bcl-2

\section{Introduction}

Cardiac remodeling (CR) is a widely used term whose meaning has progressively extended to include the manifold adaptive processes induced in heart muscle by a variety of pathological conditions such as the after-effects of myocardial infarction, hypertension, valvular diseases, familial cardiomyopathies and some hormonal intoxications. Thus, CR may be considered as a rather complex process which results from the interaction of mechanical stress with several other factors, such as ischemia and neurohormonal effects. The adaptive processes of $\mathrm{CR}$ involve changes in gene expression followed by phenotypic modifications aimed at recovery of cardiac function. However, in spite of the

\footnotetext{
* Corresponding author. Tel.: +39-55-413-765; fax: +39-55-422-2725

E-mail address: nassi@scibio.unifi.it (P. Nassi).
}

different conditions that can trigger $\mathrm{CR}$, the observed phenotypic changes are often similar since cardiomyocyte hypertrophy and alterations of intracellular $\mathrm{Ca}^{2+}$ handling are among the prominent findings [1]. Most attention, however, has been focused on late changes of $\mathrm{CR}$ while little is known about the initial molecular events that may be a prelude to the alterations described above. In this connection, an interesting - and so far unsolved - question regards the early changes in sarcoplasmic reticulum (SR) activity, which plays a key role in the intracellular $\mathrm{Ca}^{2+}$ level regulation, and the relationship between these alterations and the development of cardiomyocyte apoptosis, a condition that has been suggested to precede the hypertrophic response $[2,3]$.

Heart SR contains a $\mathrm{Ca}^{2+}$ pump which transports $2 \mathrm{~mol}$ of calcium ions into the SR lumen by utilizing $1 \mathrm{~mol}$ of ATP as a source of energy during a reaction cycle that involves the formation of acyl-phosphorylated intermediate (EP). The 
activity of cardiac SR $\mathrm{Ca}^{2+}$-ATPase (SERCA2a) is regulated by phospholamban (PLB), a 52-residue cardiac SRassociated protein whose inhibitory effect is removed by phosphorylation at either Ser-16 or Thr-17 [4]. An additional regulatory effect on the SR calcium pump might be exerted by acylphosphatase (ACPase, EC 3.6.1.7), a cytosolic enzyme, well represented in cardiac muscle, that catalyzes the hydrolysis of acylphosphates [5-7]. In previous studies, we have shown that ACPase can interact with SERCA2a and actively hydrolyze the EP intermediate of this transport system, an effect that results in an enhanced activity of the SR $\mathrm{Ca}^{2+}$ pump $[8,9]$.

Besides their consequences on cardiomyocyte contractile functioning, intracellular $\mathrm{Ca}^{2+}$ homeostasis alterations have been consistently related to apoptosis. In this regard, it is noteworthy that some anti-apoptotic or pro-apoptotic agents, notably Bcl-2 and Fas, can also affect intracellular $\mathrm{Ca}^{2+}$ distribution. Bcl-2, is a $26-\mathrm{kDa}$ protein localized, in addition to other cellular districts, in the endoplasmic reticulum (ER). In different cell types, the anti-apoptotic effect of this protein seems to depend, at least in part, on its ability to regulate $\mathrm{Ca}^{2+}$ fluxes, thus preventing an excessive ER $\mathrm{Ca}^{2+}$ pool depletion and a sustained cytosolic $\mathrm{Ca}^{2+}$ increase $[10,11]$. A similar effect of $\mathrm{Bcl}-2$ on cardiac $\mathrm{SR} \mathrm{Ca}^{2+}$ transport is conceivable, all the more so since it would fit with the well known association between the changes in SR activity and cardiac hypertrophy [12]. Fas (APO-1/CD95) is a transmembrane receptor belonging to the TNF receptor superfamily [13], constitutively present in myocytes. It is upregulated in relation to diastolic stress [14] and the interaction with its specific ligand (Fas-L) [15] results in cell-specific responses, including modification of intracellular $\mathrm{Ca}^{2+}$ levels and apoptosis $[16,17]$.

Based on this background, we decided to investigate some of the earliest aspects of CR, notably the molecular events which might represent a link between intracellular $\mathrm{Ca}^{2+}$ homeostasis alterations and cardiomyocyte apoptosis. In this connection, we have previously reported some biochemical changes occurring in heart muscle during the first $96 \mathrm{~h}$ of a pressure overload imposed by aortic banding [18]. With the aim to detect further molecular aspects of early CR, the present paper regards a study about the effects of volume overload, a condition whose morpho-functional adaptations are rather different from those observed in response to pressure overload [19]. Swine hearts, whose anatomo-functional characteristics are similar to those of the human heart, were subjected to volume overload by aortacava shunt for $6,12,24,48$ and $96 \mathrm{~h}$ in order to detect the short-term biochemical changes occurring in the left ventriculum (LV). In particular, we analyzed: (1) SERCA2a activity and expression and the relationship between the levels of this ionic pump and those of its known or potential regulators: PLB and ACPase; (2) the expressions of Bcl-2, Fas and Fas-L as possible determinants of altered $\mathrm{Ca}^{2+}$ handling as well as of cardiomyocyte apoptosis. These assays paralleled hemodynamic and echocardiographic measurements, to assess the changes in cardiac function and anatomy, and the microscopic observations aimed to detect the cellular alterations induced by our volume overload conditions.

\section{Materials and methods}

\subsection{Experimental model}

The experimental protocol described in the study conforms with the Guide for the Care and Use of Laboratory Animals published by the US National Institutes of Health (NIH Publication No. 85-23, revised 1996). Farm pigs ( $n=24$; four for each group), fasting overnight, weighing $30-45 \mathrm{~kg}$, were used. Animals were premedicated with intramuscular ketamine $(15 \mathrm{mg} / \mathrm{kg})$ and diazepam $(1 \mathrm{mg} /$ $\mathrm{kg})$. Anesthesia was induced with ketamine $(0.5 \mathrm{mg} / \mathrm{kg})$ and atropine $(0.5 \mathrm{mg} / \mathrm{kg})$ and the pigs were subsequently intubated and ventilated with oxygen supplemented with $50 \%$ $\mathrm{N}_{2} \mathrm{O}$ and fluothane at $1-1.5 \%$. Pancuronium bromide $(0.1$ $\mathrm{mg} / \mathrm{kg}$ ) was given at the beginning of the surgical procedure. The abdomen was opened via a midline incision, and the inferior part of the vena cava and abdominal aorta distal to the renal arteries were cleaned of fat and adventitia. The shunt was performed using a Dacron prosthesis $(8 \mathrm{~mm}$ diameter) which was sutured latero-laterally to the abdominal aorta and to the inferior vena cava using partial occluding clamps. When the anastomosis was performed, the clamps were released, hemostasis was obtained and the abdomen was closed. At the time of sacrifice, which was at $6,12,24,48$ and $96 \mathrm{~h}$ after surgery, the animals were again anesthetized, subjected to hemodynamic and echocardiographic measurements and then killed using humanitarian methods. After sacrifice, specimens of myocardial tissue from the LV were taken for biochemical and histological evaluation. Control animals were simply anesthetized for hemodynamic and echocardiographic measurements and immediately sacrificed.

\subsection{Hemodynamic and echocardiographic measurements}

Two $6 \mathrm{~F}$ pigtail catheters were introduced into the left femoral artery and advanced to monitor left ventricular and descending aortic pressure. A Swan-Ganz catheter was advanced from an external jugular vein to the pulmonary artery to measure pulmonary capillary wedge pressure and cardiac output (thermodilution). Two-dimensional and $\mathrm{M}$ mode echocardiographic studies $(2.25 / 3.5 \mathrm{mHz}$ transducer, SIM 5000) and relative measurements were performed on the right parasternal area and recorded on videotape [19]; wall thicknesses were measured according to the recommendations of the American Society for Echocardiography [20]. Left ventricular mass (LVM) was calculated using a validated formula [21]. Measurements were analyzed independently by two experienced echocardiographers. Inter- 
observer and intra-observer variabilities were $4.1 \pm 0.5 \%$ and $2.5 \pm 0.3 \%$ for cavity size and $3.7 \pm 0.4 \%$ and $2.1 \pm 0.3 \%$ for wall thickness, respectively.

\section{3. $\mathrm{Ca}^{2+}$-ATPase activity and $\mathrm{Ca}^{2+}$ uptake measurements}

Sarcoplasmic reticulum vesicles (SRVs), purified from cardiac LV specimens, were measured for protein [22] and used to assay $\mathrm{Ca}^{2+}$-ATPase activity and $\mathrm{Ca}^{2+}$ uptake as previously reported [18].

$\mathrm{Ca}^{2+}$-dependent ATPase activity was calculated by subtracting the basal ATPase activity (in the presence of $1 \mathrm{mM}$ Tris-EGTA) from the total $\mathrm{Ca}^{2+}$-ATPase (in presence of 10 $\mu \mathrm{M} \mathrm{Ca}^{2+}$-free). Reactions were started with ATP, and after stopping, the amount of released Pi was measured by malachite green procedure [23]. ${ }^{45} \mathrm{Ca}$ uptake was measured as the difference between ${ }^{45} \mathrm{Ca}$ influx into vesicle at time 0 and at the end of incubation ( $30 \mathrm{~s})$. The vesicles were separated by filtration through a Millipore filter $(0.45 \mu \mathrm{m}$ pore size) and the filter-trapped radioactivity was determined by liquid scintillation spectroscopy.

\subsection{ACPase activity measurement}

Cardiac LV specimens were homogenized in $0.1 \mathrm{M} \mathrm{HCl}$, adjusted to $\mathrm{pH} 7$ and centrifuged. The supernatants were assayed for protein and for activity. ACPase activity was measured by a continuous optical test at $283 \mathrm{~nm}$, using benzoyl phosphate as substrate [24]. Benzoyl phosphate was synthesized according to Camici et al. [25].

\subsection{Determination of caspase-3 activity}

Cardiac samples from control $(n=4)$ and volume-overload hearts $(n=4)$ were homogenized with a polytron homogenizer kept on ice, sonicated and centrifuged at $22000 \times g$ and $4{ }^{\circ} \mathrm{C}$ for $10 \mathrm{~min} .20 \mu \mathrm{l}$ of the supernatant were used for the measurement of the caspase- 3 activity by the CaspACE assay system, colorimetric (Promega, WI, USA). Positive control was obtained by staurosporine-induction of apoptosis in cultured rat cardiomyocytes according to Yue et al. [26]. Activity was expressed as nmol of $p$-nitroaniline (pNA) released/h/mg protein.

\subsection{Western blot analysis of SERCA2a, PLB, Bcl-2, Fas-L and ACPase}

The equivalent of $20 \mu \mathrm{g}$ of SRV protein mixtures for each lane, boiled for SERCA2a and Bcl-2, unboiled for PLB, were separated, respectively, on $12 \%$ and $15 \%$ SDS-PAGE gels. ACPase and Fas-L separation was performed on the same $15 \%$ gel using $40 \mu \mathrm{g}$ of boiled supernatant protein mixtures. The gels were electroblotted to nitrocellulose membranes that were stained with Ponceau red to confirm equal loading and transfer. After blocking nonspecific sites for $2 \mathrm{~h}$ in $5 \%$ BSA T-TBS solution $(50 \mathrm{mM}$ Tris- $\mathrm{HCl}, \mathrm{pH}$
7.4, $150 \mathrm{mM} \mathrm{NaCl}, 0.1 \%$ Tween 20) the membranes were exposed to monoclonal (mouse) anti-SERCA2a ATPase antibody (Affinity Bioreagents Inc., Golden, CO), polyclonal (rabbit) anti-ACPase antibody, purified as previously described [27], monoclonal (mouse) anti-PLB antibody (Upstate Biotechnology, Lake Placid, NY) and monoclonal (mouse) anti-Bcl-2 antibody (Oncogene Research product). For detection, a second antibody, a peroxidase-conjugated anti-rabbit IgG or anti-mouse IgG (Amersham Pharmacia Biotech, Italy) and enhanced chemiluminescence assay (Supersignal West-Dura; Pierce) were used. To detect PLB-phosphorylation status, the same nitrocellulose used to reveal PLB protein expression was stripped and reprobed with $10 \mu \mathrm{g} / \mathrm{ml}$ monoclonal (mouse) anti-P-Serine16 antibody (Sigma-Aldrich, Milano, Italy). Protein expression levels were quantified by laser densitometry using Quantity One software (Bio-Rad Laboratories). The data from densitometric analysis were normalized to protein amount loaded on the PAGE and were identical when these values were related to tubulin protein levels.

\subsection{Transmission electron microscopy}

Myocardial biopsies were taken from the LV wall of each animal, immediately fixed by immersion in cold $2.5 \%$ glutaraldehyde in $0.1 \mathrm{M}$ cacodylate buffer, $\mathrm{pH} 7.4$ at room temperature, postfixed in $1 \%$ osmium tetroxide in $0.1 \mathrm{M}$ phosphate buffer, $\mathrm{pH} 7.4$ at room temperature and routinely processed for ultrastructural analysis. Semithin sections, 2 $\mu \mathrm{m}$ thick, were cut and stained with toluidine blue-sodium tetraborate and observed under light microscope. Ultrathin sections obtained from the same specimens were placed on 200-mesh copper grids and stained with uranyl acetate and alkaline bismuth subnitrate. Approximately 200 tissue sections from control and volume-overloaded myocardium were examined under a transmission electron microscope (TEM) (JEOL 1010). In particular, three independent ultrathin sets (grids) were observed for each biopsy.

\subsection{Immunofluorescence analyses}

Immunostaining for Fas was performed on 4- $\mu$ m-thick cryosections. The tissue sections of control and volume overload hearts were incubated with $5 \mu \mathrm{g} / \mathrm{ml}$ of polyclonal (rabbit) anti-Fas antibodies (FAS-M20, Santa Cruz) and the immunoreactivity was detected with (mouse anti-rabbit) Alexa-488 conjugated secondary antibodies (Molecular Probes, Eugene OR). Negative controls for the immunoreactions were performed by substituting the primary antibodies with nonspecific serum. Counterstaining was performed using Hoechst 33342 (Molecular Probes) to reveal chromatin features. Anti-fading glycerol was used as mounting medium. A chilled CCD camera (CROMA, DTA, Italy) was used to collect images. Dual-channel signal scanning from nuclei (blue) and Fas (green) was recorded and saved in two different files. Images were signal-averaged during 
Table 1

Hemodynamic and echocardiographic changes after aorta-cava shunt

\begin{tabular}{|c|c|c|c|c|c|c|}
\hline Hours & 0 & 6 & 12 & 24 & 48 & 96 \\
\hline Heart rate (beats/min) & $82 \pm 5$ & $116 \pm 4 *$ & $112 \pm 4^{*}$ & $111 \pm 8^{*}$ & $108 \pm 8^{*}$ & $107 \pm 7 *$ \\
\hline Aortic systolic pressure $(\mathrm{mm} \mathrm{Hg})$ & $125 \pm 18$ & $113 \pm 7^{*}$ & $114 \pm 5^{*}$ & $115 \pm 4^{*}$ & $116 \pm 7$ & $117 \pm 7$ \\
\hline PWP (mm Hg) & $14 \pm 4$ & $22 \pm 5$ & $22.8 \pm 4^{*}$ & $23 \pm 4^{*}$ & $25 \pm 5^{*}$ & $21 \pm 4^{*}$ \\
\hline Cardiac output (ml/min) & $2009 \pm 463$ & $3213 \pm 417 *$ & $3422 \pm 465^{*}$ & $3549 \pm 888^{*}$ & $3370 \pm 503 *$ & $3519 \pm 203^{*}$ \\
\hline LVESP (mm Hg) & $127 \pm 23$ & $121 \pm 5$ & $123 \pm 10$ & $121 \pm 11$ & $123 \pm 5$ & $124 \pm 7$ \\
\hline LVEDP (mm Hg) & $8 \pm 2$ & $13 \pm 2 *$ & $14 \pm 3 *$ & $14 \pm 2 *$ & $15 \pm 2 *$ & $10 \pm 2$ \\
\hline DWT $(\mathrm{mm})$ & $7.8 \pm 0.7$ & $7.4 \pm 0.5$ & $7.6 \pm 0.3$ & $8.0 \pm 0.9$ & $7.9 \pm 0.9$ & $8.1 \pm 0.6$ \\
\hline SWT (mm) & $11.2 \pm 1$ & $10.9 \pm 0.3$ & $10.9 \pm 0.4$ & $11.1 \pm 0.3$ & $11.1 \pm 1.2$ & $11.4 \pm 1.1$ \\
\hline LVM $(\mathrm{g} / \mathrm{kg})$ & $2.69 \pm 0.5$ & $2.72 \pm 0.5$ & $2.70 \pm 0.3$ & $2.71 \pm 0.6$ & $3.01 \pm 0.9$ & $3.15 \pm 0.4^{*}$ \\
\hline
\end{tabular}

Values are means \pm S.D.

LVESP, left ventricular end-systolic pressure; LVEDP, left ventricular end-diastolic pressure; DWT, diastolic wall thickness; SWT, systolic wall thickness; LVM, left ventricular mass; PWP, pulmonary wedge pressure.

$* P<0.05$ vs. control.

acquisition by using the Kalman averaging option separately (five scans) to reduce noise level and improve the quality of the image.

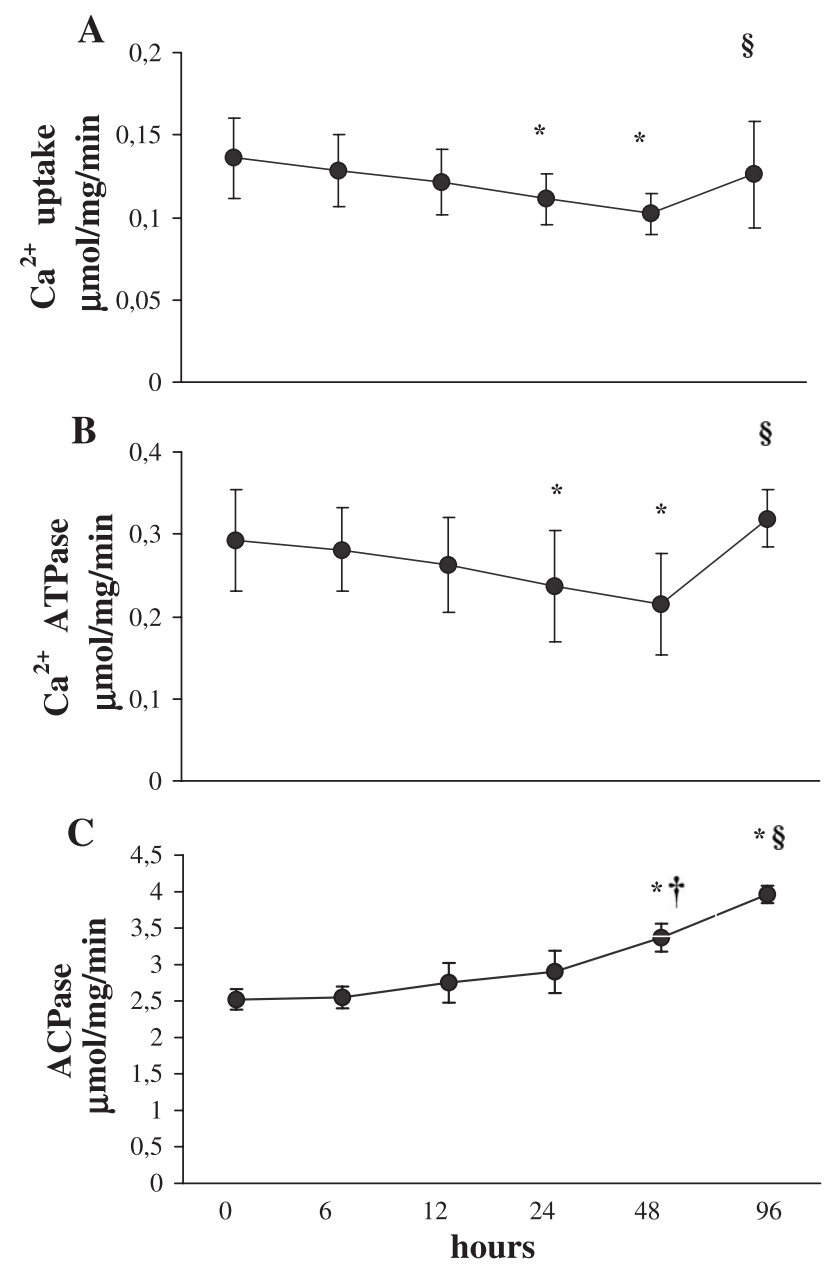

Fig. 1. Time course of $\mathrm{SR} \mathrm{Ca}^{2+}$ uptake (A), $\mathrm{Ca}^{2+}$ ATPase (B), and ACPase activities $(\mathrm{C})$ in control heart $(0)$ and in hearts subjected to volume overload. All activities are expressed as $\mu \mathrm{mol} / \mathrm{min} / \mathrm{mg}$ SR vesicle protein. Each value represents the mean value of four experiments \pm S.D. $* P<0.05$ vs. control; ${ }^{\dagger} P<0.05$ vs. $24 \mathrm{~h} ;{ }^{\S} P<0.05$ vs. $48 \mathrm{~h}$.

\subsection{Detection of apoptotic cells}

In situ end-labeling of nicked DNA (ISEL assay) was performed on paraffin-embedded sections from control and volume-overloaded LV as previously reported [28], with

\section{A}

$110 \mathrm{kDa}$
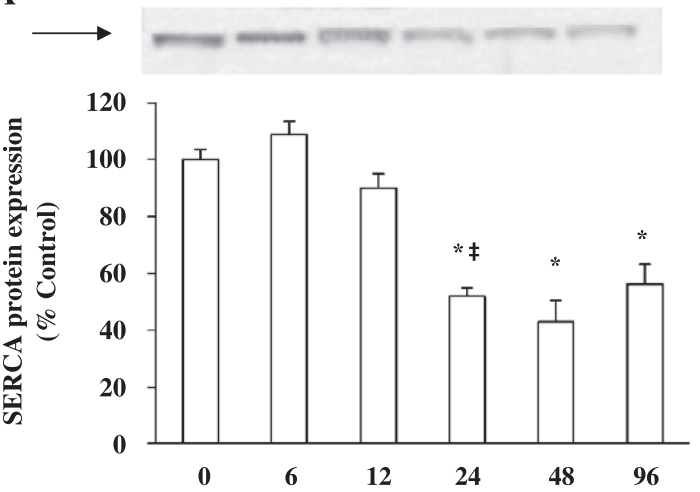

\section{B}
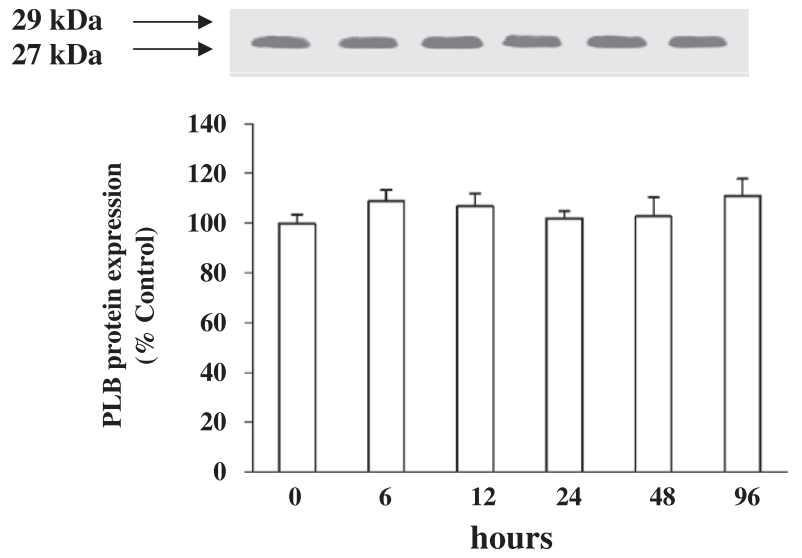

Fig. 2. Top: representative Western blotting of SERCA2a (A), and PLB (B) from control heart $(0)$ and hearts subjected to volume overload. Bottom: quantitative data. Each bar represents the mean value \pm S.D. of four different blots. Signals were quantified by densitometric analysis and are expressed as a percentage of the control value. No significant changes were observed for PLB protein expression. ${ }^{*} P<0.05$ vs. control; ${ }^{\ddagger} P<0.05$ vs. $12 \mathrm{~h}$. 
A

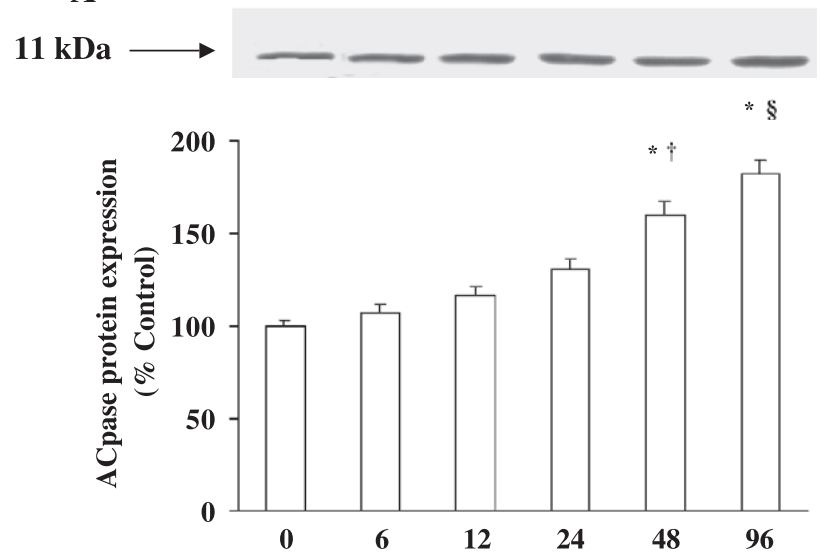

B
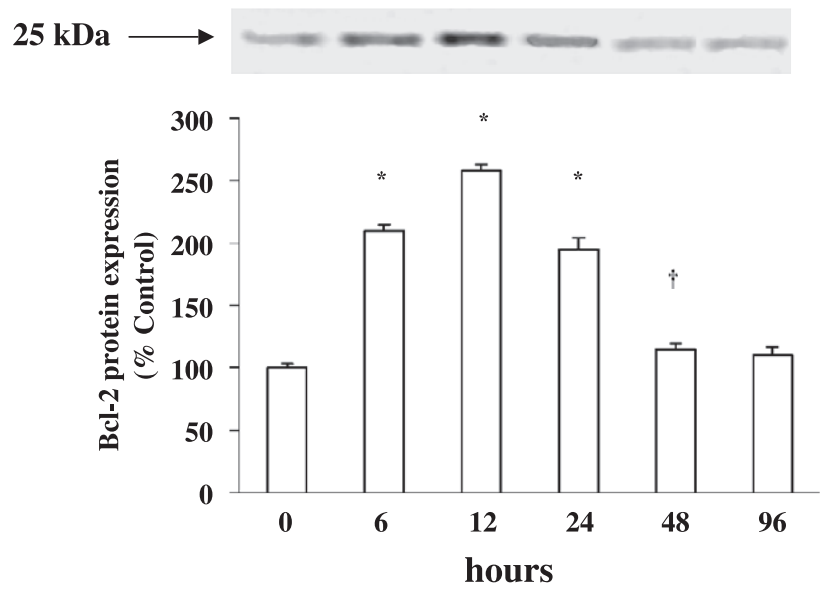

Fig. 3. Top: representative Western blotting of ACPase (A) and Bcl-2 (B) from control heart $(0)$ and hearts subjected to volume overload. Bottom: quantitative data. Each bar represents the mean value \pm S.D. of four different blots. Signals were quantified by densitometric analysis and are expressed as a percentage of the control value. $* P<0.05$ vs. control; ${ }^{\dagger} P<0.05$ vs. 24 h; ${ }^{\S} P<0.05$ vs. 48 h.

minor modifications. Briefly, the sections were incubated first with the Klenow fragment of DNA polymerase I and biotylinated deoxynucleotides (FRAGEL-Klenow, DNA fragmentation kit, Calbiochem, CA) and then with streptoavidin-peroxidase and finally stained with diaminobenzidine tetrahydrochloride (DAB). Counterstaining was performed with methyl green. LV Apoptotic nuclei were easily recognized by the presence of a dark brown staining in contrast with that of necrotic and mitotic cells which instead appeared weakly stained. Viable cells appeared green. The number of viable green-stained as well as of apoptotic cardiomyocytes in ISEL-stained sections were

Fig. 4. Detection of LV Fas expression by immunofluorescence. No staining was detected in the control myocardium (A). In the myocardial tissue sections from 48 (B) and $96 \mathrm{~h}$ (C) of volume overload, the immunoreaction appears mostly granular throughout the fibers with a slight enhancement of subsarcolemmal staining. Note that only after $48 \mathrm{~h}$ of overload (B), is the immunostaining associated with the occurrence of apoptotic nuclei (arrows) and apoptotic body formation (arrowheads).
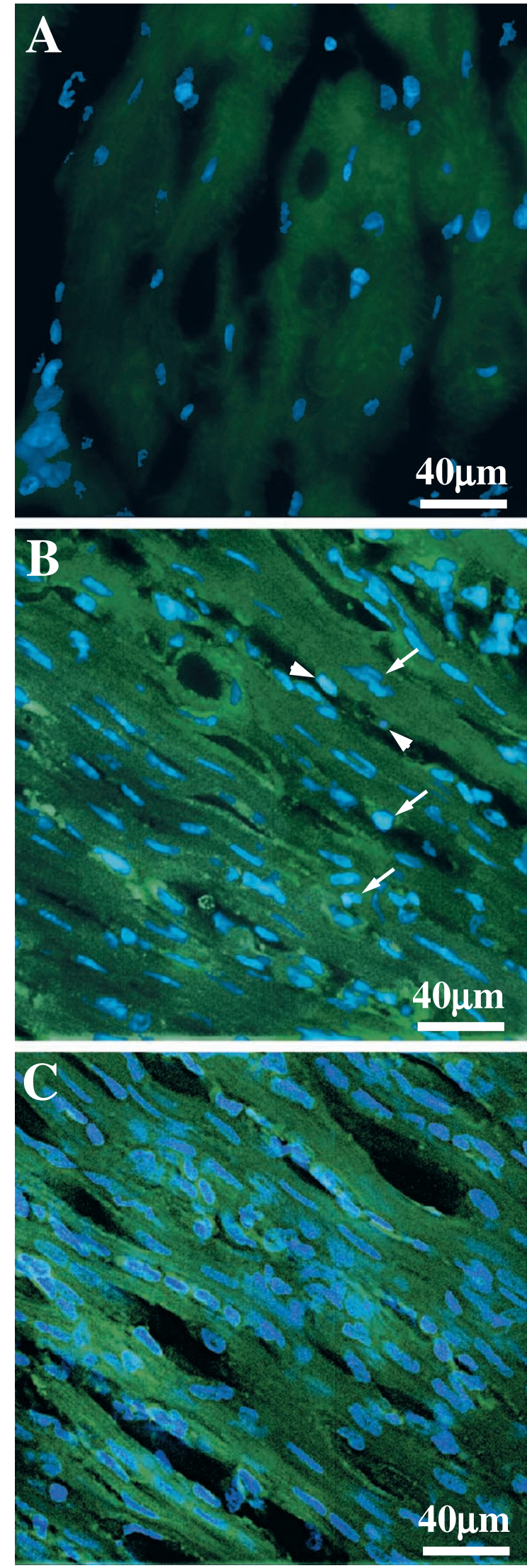
counted using an LM with an ocular grid (area of the field $\left.=26300 \mu \mathrm{m}^{2}\right)$ at $40 \times$. An average of 384 microscopic fields (four in each section for a total of three sections for each biopsy examined) were analyzed by two different observers and the individual values were then averaged. The cardiomyocyte nuclei were identified by the standard morphological criterion: typical ovoid nucleus included in the cross-striated cytoplasm of myocardial fibers in transversally oriented section.

\subsection{Measurement of cell size}

Additional sections from paraffin-embedded tissue were stained with $1 \%$ toluidine-blue. At each experimental time, 10 myocytes from six randomly selected optical fields in each transversely sectioned specimen (three from each animal) of $26300 \mu \mathrm{m}^{2}$ were analyzed at a magnification of $40 \times$ by Adobe Photoshop Program. The area of individual cells containing well-defined round nuclei, were measured using Scion Image Program.

\subsection{Statistics}

All data are presented as mean \pm standard deviation (S.D.). Comparisons between the different groups were performed by ANOVA followed by the Bonferroni $t$-test. A value of $P<0.05$ was accepted as statistically significant.

\section{Results}

\subsection{Hemodynamic data}

During the study period, the aorta-cava fistula remained pervious in all the operated pigs and no animal showed signs of heart failure. The data reported in Table 1 indicate that, although systolic and diastolic wall thickness was substantially unchanged, our overloaded hearts developed hypertrophic response, since $96 \mathrm{~h}$ after surgery, their LVM was significantly higher with respect to the control value. The changes in cardiac output were consistent with the imposed overload conditions. No significant modifications were observed for left ventricular end-systolic pressure (LVESP) while left ventricular end-diastolic pressure (LVEDP), taken as an index inversely correlated with heart contractility, was significantly increased $6 \mathrm{~h}$ after surgery. After having attained a maximum level after $48 \mathrm{~h}$ of overload, LVEDP decreased and at $96 \mathrm{~h}$ it was not significantly different from the control value. The changes in LVEDP were similar to those observed for pulmonary wedge pressure, although at $96 \mathrm{~h}$ they were still over the control level.

\subsection{Biochemical data}

The early functional changes of SR $\mathrm{Ca}^{2+}$ pump function were represented by a parallel and progressive decrease in the rates of $\mathrm{Ca}^{2+}$-dependent ATP hydrolysis and $\mathrm{Ca}^{2+}$
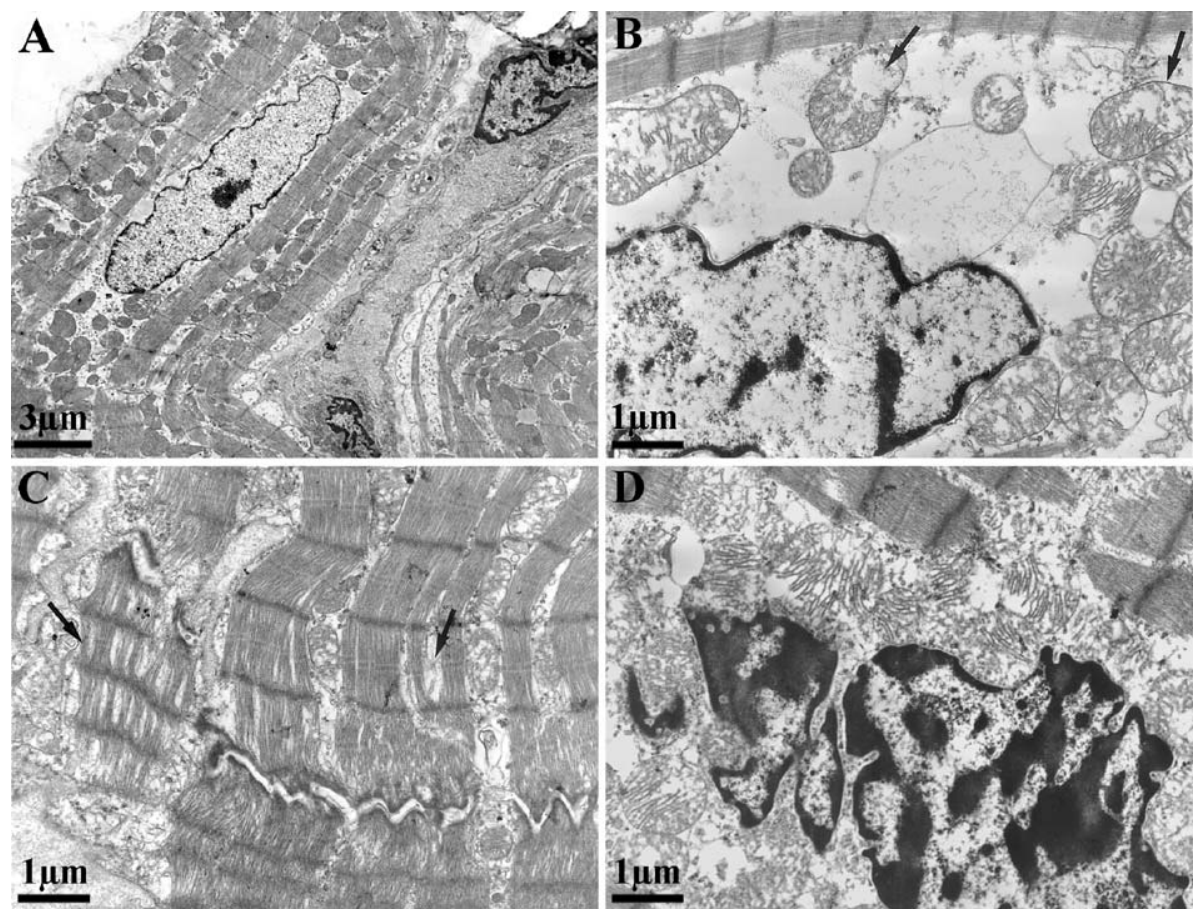

Fig. 5. TEM of 96-h volume-overloaded (A) and 48-h volume-overloaded (B, C, D) myocardium. (A) Two cardiomyocytes display an ultrastructural pattern quite superimposable to the controls. (B) A prominent intracellular edema associated with swelling of mitochondria (arrows) is visible in panel B. (C) Signs of myofibrillar disarray consisting in loss of myofilaments (arrows) are shown in two adjacent cardiomyocytes. (D) A cardiomyocyte nucleus, displaying apoptotic features, i.e. highly condensed chromatin clumps against the nuclear envelope, is shown. 

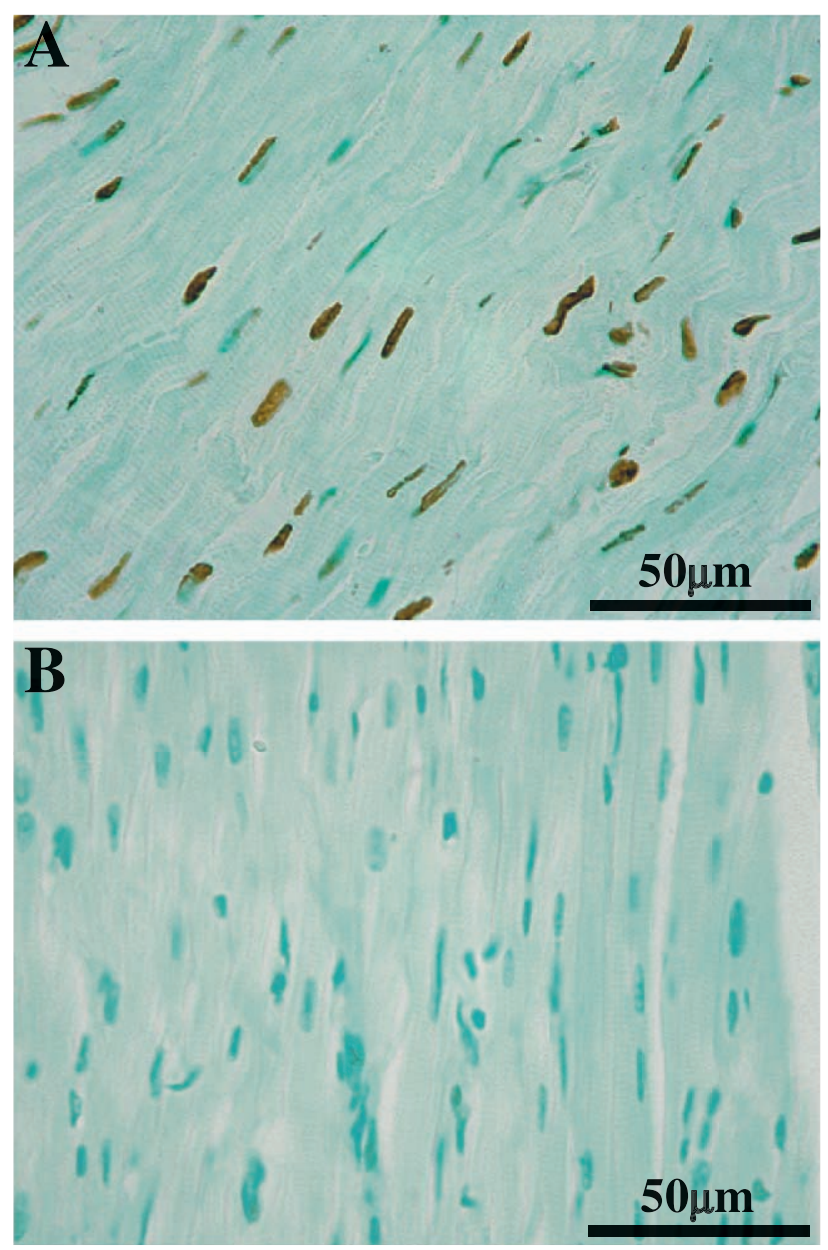

Fig. 6. Detection of apoptotic cells by ISEL assay of fragmented DNA. (A) Representative light microscopic micrograph of $48 \mathrm{~h}$ volume-overloaded myocardium. Note that some cardiomyocytes exhibit dark brown-stained ISEL-positive nuclei. (B) Light microscopic micrograph of control myocardium. Virtually no cardiomyocyte stain is positive for apoptotic nuclear fragmentation.

uptake that $48 \mathrm{~h}$ after surgery appeared significantly reduced to about $30 \%$ of control values. At $96 \mathrm{~h}$, these activities were not significantly different from the control value showing a functional recovery of SR $\mathrm{Ca}^{2+}$ pump function (Fig. 1A and B). However, SERCA2a protein expression, assessed by Western blot analysis, reflected only in part the modifications of $\mathrm{Ca}^{2+}$ pump activity. In fact, it was significantly reduced after $24 \mathrm{~h}$ and, even more, after $48 \mathrm{~h}$ of overload, but this decrease was more marked (about 60\% below the control value) and remained at a low level, in spite of the recovery of functional SR properties.
The immunochemical detection of PLB in unboiled protein samples and its densitometric analysis showed no significant modifications at all the considered times (Fig. 2B). Nor was PLB-phosphorylation status modified, according to the immunodetectable signals revealed by using a specific antibody that exclusively detects PLB at its Ser-16 phosphorylated site (data not shown).

On the other hand, acylphosphatase activity significantly increased from $48 \mathrm{~h}$ of overload reaching at $96 \mathrm{~h}$ a mean level that was about $40 \%$ higher than the control value (Fig. 1C). A similar trend was observed for ACPase protein expression (Fig. 3A).

We also found significant changes in the expression of Bcl-2. As shown in Fig. 3B, Bcl-2 protein expression in overloaded hearts increased significantly at 6,12 and 24 $\mathrm{h}$ after surgery, but returned to levels not significantly different from control values at $48 \mathrm{~h}$.

As for Fas/Fas-L expression, the immunofluorescence analysis showed that the incubation of myocardial samples with the anti-Fas $\mathrm{mAb}$ resulted in a specific green staining representing Fas receptor expression, which was detected not only on the sarcolemma but also within the cytoplasm of cardiomyocytes exposed to the increased workload (Fig. 4). The immunostaining, undetectable in the tissue sections of the control and in the hearts until $24 \mathrm{~h}$ of overload, became clearly evident at $48 \mathrm{~h}$ when the co-staining with Hoechst 33342 showed typical apoptotic features (Fig. 4B). After 96 $\mathrm{h}$ of overload, Fas expression was still higher than the control value, but the apoptotic signs disappeared (Fig. 4C).

Western blot analysis of Fas-L showed that the expression of this protein was revealed in volume-overloaded hearts compared with undetectable levels in control myocardium (data not shown).

\subsection{Morphological data and assessment of cardiomyocyte apoptosis}

Morphological analysis performed in parallel with biochemical measurements revealed that overloaded myocardium underwent a period of remarkable ventricular remodeling consisting of the occurrence of several damaged cardiomyocytes which were focally distributed within the myocardium. These modifications were evident at $48 \mathrm{~h}$ after surgery and disappeared in the later phases $(96 \mathrm{~h})$ of the experimentation (Fig. 5A-D). Evidence of cardiomyocyte damage included a prominent intracellular edema accumulation, enlarged nuclei, swollen mitochondria, and in the appearance of focal areas of sarcomere hypercontractions

Table 2

Apoptotic nuclei number/ $1 \mathrm{~mm}^{2}$ (A) and caspase-3 activity (nmol pNA/h per mg protein) (B)

\begin{tabular}{lcccccc}
\hline Hours & 0 & 6 & 12 & 24 & 48 & 96 \\
\hline A & $0.72 \pm 0.15$ & $18.3 \pm 8.82^{*}$ & $16.5 \pm 672^{*}$ & $19.9 \pm 5.96^{*}$ & $34.7 \pm 11.10^{*}$ & $10.9 \pm 5.36^{*}$ \\
B & $2.55 \pm 0.11$ & $3.07 \pm 0.14^{*}$ & $3.01 \pm 0.09^{*}$ & $3.24 \pm 0.13^{*}$ & $5.22 \pm 0.18^{*}$ & $3.41 \pm 0.10^{*}$ \\
\hline
\end{tabular}

Values are means \pm S.D.

$* P<0.05$ vs. control. 
Table 3

Cardiomyocyte cross-section area $\left(\mu \mathrm{m}^{2}\right)$ after aorta-cava shunt

\begin{tabular}{lccccc}
\hline Hours & 0 & 6 & 12 & 24 & 48 \\
\hline$\mu \mathrm{m}^{2}$ & $225.31 \pm 32.69$ & $249.20 \pm 33.21$ & $252.20 \pm 35.31$ & $266.60 \pm 33.21$ & $280.05 \pm 58.31$ \\
\hline
\end{tabular}

Values are means \pm S.D.

$* P<0.05$ vs. control.

associated with overstretched myofilaments (Fig. 5A-C). Concomitant with the occurrence of these ultrastructural alterations, evidence of cardiomyocyte apoptosis could also be observed (Fig. 5D). With the use of ISEL method, apoptotic nuclei could be easily detected in cardiomyocytes exposed to $48 \mathrm{~h}$ of volume overload (Fig. 6B) compared to the control (Fig. 6A) and other times (data not shown). The quantitative analysis of the number of nuclei positively stained for ISEL confirmed the visual findings, showing a wave of apoptosis which peaked at $48 \mathrm{~h}$ after surgery (Table 2A). In particular, in the 48-h overloaded myocardium, the number of apoptotic cells represented approximately $12 \%$ of the total number of cardiomyocytes. At $96 \mathrm{~h}$ after surgery, the number of apoptotic nuclei was markedly reduced, at about $4 \%$ of the total number of cardiomyocytes, while a significant increase in the cross-sectional areas of cardiomyocytes became evident (Table 3).

The ISEL data about cardiomyocyte apoptosis was consistent with the time course of caspase- 3 activity, which we measured as a typical biochemical marker of this process (Table 2B).

\section{Discussion}

The aim of the present investigation was to identify some aspects of CR, notably the early adaptive processes occurring in heart LV in response to a volume overload. For this study, we used a well-accepted animal model, swine hearts subjected to volume overload by an aorta-cava shunt, and an approach based on the simultaneous survey of hemodynamic, biochemical and morphological changes induced by these experimental conditions within the first $96 \mathrm{~h}$.

The results of hemodynamic and echocardiographic measurements indicate a precocious development of a hypertrophic reaction and a transient loss of contractility which peaked $24 \mathrm{~h}$ after surgery, followed by a progressive recovery, resulting in the restoration of control values after $96 \mathrm{~h}$. While the hypertrophic response, indicated by the data regarding LVM, was consistent with the microscopic findings, the time course of the changes in LV contractility substantially reproduced the observed modification of SR function, in agreement with several reports from which it appears that modifications in intracellular $\mathrm{Ca}^{2+}$ handling play a major role in the adaptation of heart muscle to an increased working load $[29,30]$. As regards the factors responsible for the changes in SR activity, our findings, notably the absence of a parallelism between the time course of $\mathrm{Ca}^{2+}$ pump and of SERCA2a protein expression, support the involvement of a mechanism acting on the functional properties rather than on the mass concentration of $\mathrm{SR} \mathrm{Ca}^{2+}$ pump. In this connection, the regulatory role of PLB is well known and it is accepted that enhanced $\mathrm{Ca}^{2+}$ pump activity may result either from a decrease in relative PLB/SERCA ratio or from an increase in PLB phosphorylation status [4]. Our measurements, however, indicate that PLB did not undergo significant changes in its protein expression nor in its phosphorylation status at Ser-16 residue, which is the prerequisite for other residue phosphorylation at all experimental times. These results allow us to exclude a PLB involvement of in the changes of $\mathrm{Ca}^{2+}$ pump activity in our overloaded hearts.

Conversely, a novel finding emerging from the present studies is that ACPase levels gradually rose with respect to control values and, from $48 \mathrm{~h}$ after surgery, this enzyme exhibited a significant increase not only in its activity but also in its protein expression. As stated above, ACPase appears to affect the functional properties of SERCA2a by stimulating $\mathrm{Ca}^{2+}$ pump activity. Our studies also suggest that the ACPase effect was mainly due to its hydrolytic activity on the SR $\mathrm{Ca}^{2+}$ pump EP [8]; however, because of a structural analogy with PLB, ACPase might also interact with SERCA2a [9], taking the place of unphosphorylated PLB and removing the inhibitory effect of this protein, as recent studies have underlined [31]. In any case, given this stimulatory effect - in whatever way it is exerted - and the time course of ACPase levels, it seems reasonable to propose that our enzyme may be responsible, at least in part, for the recovery of $\mathrm{Ca}^{2+}$ pump activity.

Another original aspect of our results regards a possible involvement of $\mathrm{Bcl}-2$ in the controlling of heart SR $\mathrm{Ca}^{2+}$ transport. Bcl-2 was considered in the present study because several reports indicate that this protein can regulate the movements of $\mathrm{Ca}^{2+}$ through ER membrane, notably that Bcl-2 overexpression leads to increased ER calcium loading due to an enhancement of $\mathrm{Ca}^{2+}$ uptake $[10,11]$. In fact, although the mechanisms for this effect are controversial, they include a direct interaction with SERCA2a and the possibility that Bcl-2, as suggested by X-ray and NMR analysis, could form ionic channels in ER membrane [32]. Based on these findings, and supposing a similar action on cardiac SR, we measured Bcl-2 protein expression and found that it was significantly increased over the control levels after 6, 12 and $24 \mathrm{~h}$ of volume overload; these changes in Bcl-2 expression were temporarily associated with a decrease in $\mathrm{Ca}^{2+}$ pump activity which, however, was less marked than the concomitant reduction in SERCA2a protein levels. Although this finding does not provide 
evidence for a cause-effect relationship, it should be noted that at the times in question, both PLB and acylphosphatase levels were unchanged, thus it seems reasonable to suppose that lack of correspondence between SERCA2a activity and protein concentration may be ascribed to an enhanced SR $\mathrm{Ca}^{2+}$ uptake due to Bcl-2 overexpression. Another property of Bcl-2, likely related to its action on calcium handling is its anti-apoptotic function [10,11,32,33], which contrasts with the pro-apoptotic function of Fas/Fas-L system $[16,17]$. In this regard, our overloaded hearts showed signs of sufferance and of cardiomyocyte apoptosis which, until $24 \mathrm{~h}$, was limited by Bcl-2 overexpression but peaked at 48 $\mathrm{h}$ after surgery, just before the hypertrophic response became evident, when Bcl-2 expression returned to control values and SERCA2a activity and expression reached the lowest levels. This could contribute to an upregulation of sarcoplasmic $\mathrm{Ca}^{2+}$ levels, resulting in the activation of proteases, nucleases and other calcium-dependent enzymes, a possible cause of the observed morphological changes and of cardiomyocyte apoptosis [34]. In addition to the reduced activity of SR $\mathrm{Ca}^{2+}$ pump, another determinant of the supposed $\mathrm{Ca}^{2+}$ overload, might be represented by Fas activation. In fact, after $48 \mathrm{~h}$ of overload, Fas levels were enhanced, in agreement to Wollert et al. [14], who report an overexpression of this receptor in relation with volume overload. In concomitance with the increased Fas expression, also Fas-L became detectable in volume-overloaded hearts, hence the possibility of the activation of this signaling pathway. As suggested by several groups, the manifold action produced by Fas activation included a prominent elevation of $\mathrm{Ca}^{2+}$ levels, an effect which is probably mediated by inositol 1,4,5-triphosphate through a leakage of $\mathrm{Ca}^{2+}$ from intracellular stores and/or a transmembrane $\mathrm{Ca}^{2+}$ influx [17]. Fas activation might also be involved in the development of cardiomyocyte hypertrophy which appeared in the last phase of our experimental period. This possibility is suggested by the recent report of Badorff et al. [35], who found that a functional Fas receptor is required for the compensatory hypertrophy in response to hemodynamic overload, and by our findings, which indicate the persistence of high Fas levels even $96 \mathrm{~h}$ after surgery.

In conclusion, the results of the present study indicate that, in our model of volume overload, the early CR responses involve significant structural and functional changes which are mainly evident after $48 \mathrm{~h}$ but are markedly attenuated at $96 \mathrm{~h}$. At this time, in particular, SERCA2a activity was completely restored, which appears to be in contrast with the late changes observed in chronically failing hearts, where most reports indicated that the function of this calcium pump is markedly depressed (B). At present we cannot provide satisfactory explanation for this discordance, we only limit to focus that, as above stated, the early recovery of SERCA2a activity is not attained by changes in the levels of this protein, but owing to stimulatory effects that might become exhausted at a later stage. In any case, although the molecular mechanisms that could link the hemodynamic overload to our findings remain to be elucidated, the results of this study raise two intriguing possibilities. First, the involvement of Bcl-2 and ACPase in the modulation of SERCA2a activity, notably the role of Bcl-2 in preventing an excessive reduction during the initial phases of overload and of ACPase in the subsequent recovery of the calcium function. Second, the eventuality that cardiomyocyte apoptosis, a prerequisite for the development of cardiac hypertrophy, is triggered by a decline, until to a return to basal levels, of Bcl-2 and by a concomitant overexpression and activation of Fas: a result which might be consistent with the opposite effects of these agents on heart intracellular $\mathrm{Ca}^{2+}$ distribution.

In our opinion, further studies would be of interest to verify these possibilities, and to probe more deeply, even in different experimental models, their importance for the adaptive processes of CR.

\section{Acknowledgements}

The financial support of Telethon-Italy (Grant no. 1132) is gratefully acknowledged.

\section{References}

[1] B. Swinghedauw, Molecular mechanisms of myocardial remodeling, Physiol. Rev. 79 (1999) 215-262.

[2] Q. He, D.I. Lee, R. Rong, M. Yu, X. Luo, M. Klein, W.S. El-Deiry, Y. Huang, A. Hussain, M.S. Sheikh, Endoplasmic reticulum calcium pool depletion-induced apoptosis is coupled with the activation of death receptor 5 pathway, Oncogene 21 (17) (2002) 2623-2633.

[3] E. Teiger, T.-V. Dam, C. Richard, C. Wisnewsky, B.S. Tea, L. Gaboury, J. Tremblay, K. Schwartz, P. Hamet, Apoptosis in pressureoverload-induced heart hypertrophy in the rat, J. Clin. Invest. 97 (1996) 2891-2897.

[4] H.K. Simmerman, L.R. Jones, Phospholamban: protein structure, mechanism of action, and role in cardiac function, Physiol. Rev. 78 (1998) 921-947.

[5] A. Berti, M. Stefani, G. Liguri, G. Camici, G. Manao, G. Ramponi, Acylphosphatase action on dicarboxylic acylphosphates, Ital. J. Biochem. 26 (1977) 377-378.

[6] G. Ramponi, F. Melani, A. Guerritore, Azione dell' acilfosfatasi di muscolo sul carbamilfosfato, J. Biochim. 10 (1961) 189-196.

[7] G. Ramponi, C. Treves, A. Guerritore, Hydrolytic activity of muscle acylphosphatase on 3-phosphoglyceroyl-phosphate, Experientia 23 (1967) 1019-1020.

[8] C. Nediani, C. Fiorillo, E. Marchetti, A. Pacini, G. Liguri, P. Nassi, Stimulation of cardiac sarcoplasmic reticulum calcium pump by acylphosphatase, relationship to phospholamban phosphorylation, J. Biol. Chem. 271 (1996) 19066-19073.

[9] C. Nediani, C. Fiorillo, S. Rigacci, F. Magherini, M. Francalanci, G. Liguri, A. Pacini, P. Nassi, A novel interaction mechanism accounting for different acylphosphatase effects on cardiac and fast twitch skeletal muscle sarcoplasmic reticulum calcium pumps, FEBS Lett. 443 (1999) 308-312.

[10] H. He, M. Lam, T.S. McCormick, C.W. Distelhorst, Maintenance of calcium homeostasis in the endoplasmic reticulum by Bcl-2, J. Cell Biol. 138 (1997) 1219-1228.

[11] T.H. Kuo, H.R.-C. Kim, L. Zhu, Y. Yu, H.-M. Lin, W. Tsang, Mod- 
ulation of endoplasmic reticulum calcium pump by Bcl-2, Oncogene 17 (1998) 1903-1910.

[12] S.R. Houser, V. Piacentino III, J. Wesser, Abnormalities of calcium cycling in the hypertrophied and failing heart, J. Mol. Cell. Cardiol. 32 (2000) 1595-1607.

[13] A. Oehm, I. Behrmann, W. Falk, M. Pawlita, G. Maier, C. Klas, M. Li-Weber, S. Richards, J. Dhein, B.C. Trauth, H. Ponstingl, P.H. Krammer, Purification and molecular cloning of the APO-1 cell surface antigen, a member of the tumor necrosis factor/nerve growth factor receptor superfamily: sequence identity with the Fas antigen, J. Biol. Chem. 267 (1992) 10709-10715.

[14] K.C. Wollert, J. Heineke, J. Westermann, M. Ludde, B. Fiedler, W. Zierhut, D. Laurent, M.K.A. Bauer, K. Schulze-Osthoff, H. Drexler, The cardiac Fas (APO-1/CD95) receptor/Fas ligand system: relation to diastolic wall stress in volume-overload hypertrophy in vivo and activation the transcription factor AP-1 in cardiac myocytes, Circulation 101 (2000) 1172-1178.

[15] T. Suda, T. Takahashi, P. Golstein, S. Nagata, Molecular cloning and expression of the Fas ligand, a novel member of the tumor necrosis factor family, Cell 75 (1993) 1169-1178.

[16] N. Itoh, S. Yonehara, A. Ishii, M. Yonehara, S.I. Mizuhima, M. Sameshima, A. Hase, Y. Seto, S. Nagata, The polypeptide encoded by the cDNA for human cell surface antigen Fas can mediate apoptosis, Cell 66 (1991) 233-243.

[17] B. Felzen, M. Shilkrut, H. Less, I. Sarapov, G. Maor, R. Coleman, R.B. Robinson, G. Berke, O. Binah, Fas (CD95/APO-1)-mediated damage to ventricular myocytes induced by cytotoxic $\mathrm{T}$ lymphocytes from perforin-deficient mice: a major role for inositol 1,4,5-triphosphate, Circ. Res. 82 (1998) 438-450.

[18] C. Nediani, L. Formigli, A.V. Perna, L. Ibba-Manneschi, S. ZecchiOrlandini, C. Fiorillo, V. Ponziani, C. Cecchi, P. Liguori, G. Fratini, P. Nassi, Early changes induced in the left ventricle by pressure overload. An experimental study on swine heart, J. Mol. Cell. Cardiol. 32 (2000) 131-142.

[19] P.A. Modesti, S. Vanni, I. Bertolozzi, I. Cecioni, G. Polidori, R. Paniccia, B. Bandinelli, A. Perna, P. Liguori, M. Boddi, G. Galanti, G.G. Neri Serneri, Early sequence of cardiac adaptations and growth factor formation in pressure- and volume-overload hypertrophy, Am. J. Physiol., Heart Circ. Physiol. 279 (2000) H976-H985.

[20] D.J. Sahn, A. De Maria, J. Kisslo, A. Weyman, Recommendations regarding quantitation in M-mode echocardiography: results of a survey of echocardiographic measurements, Circulation 58 (1978) $1072-1083$.

[21] M.P. Feneley, J.W. Gaynor, G.W. Maier, S.A. Gall Jr., J.A. Kisslo, J.S. Rankin, In vivo estimation of left ventricular wall volume in volumeoverloaded canine hearts, Am. J. Physiol., Heart Circ. Physiol. 255 (1988) H1399-H1404.

[22] G. Beisenherz, H.J. Boltze, T.H. Bucher, R. Czok, K.H. Garbade, E.
Meyer-Arendt, G. Pfleiderer, Diphosphofructosealdolase, phosphoglyceraldehyd-dehydrogenase, milchsauredehydrogenase and pyruvat-kinase aus kaninchen-muskulature in einern arbeitsgang, $\mathrm{Z}$. Naturforsch. 8b (1953) 555-577.

[23] A.A. Baykov, O.A. Evtushenko, S.M. Avaeva, A malachite green procedure for orthophosphate determination and its use in alkaline phosphatase-based enzyme immunoassay, Anal. Biochem. 171 (1988) 266-270.

[24] G. Ramponi, C. Treves, A. Guerritore, Continuous optical assay of acylphosphatase with benzoyl phosphate as substrate, Experientia 22 (1966) $705-706$.

[25] G. Camici, G. Manao, G. Cappugi, G. Ramponi, A new synthesis of benzoyl phosphate: a substrate for acylphosphatase assay, Experientia 32 (1976) 535-536.

[26] T.L. Yue, C. Wang, A.M. Romanic, K. Kikly, P. Keller, W.E. De Wolf, T.K. Hart, H.C. Thomas, B. Storer, J.L. Gu, X. Wang, G.Z. Feuerstein, Staurosporine-induced apoptosis in cardiomyocytes: a potential role of caspase-3, J. Mol. Cell. Cardiol. 30 (1998) 495-507.

[27] A. Berti, G. Liguri, M. Stefani, P. Nassi, G. Ramponi, Purification of horse muscle acylphosphatase antibodies by affinity chromatography, Physiol. Chem. Phys. 14 (1982) 307-311.

[28] J.H. Wijsman, R.R. Jonker, R. Keijzer, C.J.H. Van de Velde, C.J. Cornelisse, J.H. van Dierendonck, A new method to detect apoptosis in paraffin sections: in situ end-labeling of fragmented DNA, J. Histochem. Cytochem. 41 (1993) 7-12.

[29] T. Ohkusa, Y. Hisamatsu, M. Yano, S. Kobayashy, H. Tatsuno, Y. Saiki, M. Kohno, M. Matsuzaki, Altered cardiac mechanism and sarcoplasmic reticulum function in pressure-overload cardiac hypertrophy in rats, J. Mol. Cell. Cardiol. 29 (1997) 45-54.

[30] S.R. Houser, V. Piacentino III, J. Wesser, Abnormality of calcium cycling in the hypertrophied and failing heart, J. Mol. Cell. Cardiol. 32 (2000) 1595-1607.

[31] C. Nediani, A. Celli, C. Fiorillo, V. Ponziani, L. Giannini, P. Nassi, Acylphosphatase interferes with SERCA2a-PLN association, Biochem. Biophys. Res. Commun. 301 (4) (2003) 948-951.

[32] S.W. Muchmore, M. Sattler, H. Liang, R.P. Meadows, J.E. Harlaw, H.S. Yoan, D. Nettesheim, B.S. Chang, C.B. Thomposon, S.L. Wang, S.L. Ng, S.W. Fesie, X-ray and NMR structure of human Bcl-xL, an inhibitor of programmed cell death, Nature 381 (1996) 335-341.

[33] O.L. Deveraux, S.L. Schendel, J.C. Reed, Antiapoptotic proteins. The Bcl-2 and inhibitor of apoptosis protein families, Cardiol. Clin. 19 (2001) 57-74 (Review).

[34] S. Orrenius, P. Nicotera, The calcium ion and cell death, J. Neural Transm. 43 (1994) 1-11.

[35] C. Badorff, H. Ruetten, S. Mueller, M. Stahmer, D. Gehring, F. Jung, C. Ihling, A.M. Zeiher, S. Dimmerler, Fas receptor signaling inhibits glycogen synthase kinase $3 \beta$ and induces cardiac hypertrophy following pressure overload, J. Clin. Invest. 109 (2002) 373-381. 